\title{
Breastfeeding patterns and risk of childhood acute lymphoblastic leukaemia
}

\author{
ML Kwan*,', PA Buffler', JL Wiemels², C Metayer', S Selvin', JM Ducore ${ }^{3}$ and G Block' \\ 'Division of Public Health Biology and Epidemiology, School of Public Health, University of California, Berkeley, CA 94720, USA; ${ }^{2}$ Department of \\ Epidemiology and Biostatistics, School of Medicine, University of California, San Francisco, CA 94 I43, USA; ${ }^{3}$ Department of Pediatrics, Section of \\ Hematology/Oncology, University of California, Davis, Sacramento, CA 95817, USA
}

\begin{abstract}
The risk of childhood acute lymphoblastic leukaemia (ALL) was investigated in relation to breastfeeding patterns in the Northern California Childhood Leukaemia Study. Data collected by self-administered and in-person questionnaires from biological mothers of leukaemia cases (age 0-14 years) in the period 1995-2002 were matched to birth certificate controls on date of birth, sex, Hispanic ethnic status, and maternal race. Ever compared to never breastfeeding was not associated with risk of ALL at ages I - I4 years (odds ratio $=0.99 ; 95 \% \mathrm{Cl}=0.64-1.55)$ and ages $2-5$ years $(\mathrm{OR}=1.49 ; 95 \% \mathrm{Cl}=0.83-2.65)$. Various measures of breastfeeding duration compared to absence of breastfeeding also had no significant effect on risk. Complimentary feeding characteristics such as type of milk/formula used and age started eating solid foods among breastfed children were not associated with ALL risk. This study provides no evidence that breastfeeding affects the occurrence of childhood ALL.
\end{abstract}

British Journal of Cancer (2005) 93, 379-384. doi: I0.1038/sj.bjc.6602706 www.bjcancer.com

Published online 19 July 2005

(c) 2005 Cancer Research UK

Keywords: child; leukaemia; acute lymphoblastic leukaemia; breastfeeding; infection

For several decades, an infectious aetiology has been postulated as a cause of leukaemia in children (Heath and Hasterlik, 1963; Greaves, 1988; Kinlen, 1988; Severson et al, 1989; Doody et al, 1992), together with supporting evidence (Kinlen, 2000; Ma et al, 2002; Perrillat et al, 2002a, b; Jourdan-Da Silva et al, 2004).

One particular hypothesis by Greaves (Greaves, 1999; Greaves and Wiemels, 2003) holds that common B-cell precursor acute lymphoblastic leukaemia (c-ALL) arises as a consequence of a rare, abnormal response to nonspecific, common infections in two genetic events. As a first step, a spontaneous genetic alteration, often a chromosomal translocation, occurs during the expansion of B-cell precursors in the pre- or perinatal period. Subsequently, a second mutational event arises following antigenic challenge early in life. Support for the first step is seen in genetic backtracking of the TEL-AML1 translocation, a genetic mutation contributing to c-ALL (Wiemels et al, 1999; McHale et al, 2003).

Within the context of the Greaves' hypothesis, it is postulated that maternal breastfeeding may protect against childhood ALL by modulating the child's immune system early in life to respond effectively during exposure to common infections later in life. (Davis, 1998; Greaves, 1999). To date, a number of studies have explored the relationship between breastfeeding and childhood leukaemia risk (Kwan et $a l, 2004 \mathrm{~b}$ ) with inconsistent results (Davis, 1998), but the overall trend suggests a protective effect (Davis, 1998; Kwan et al, 2004b).

* Correspondence: Dr ML Kwan, University of California, Berkeley, 2I50 Shattuck Ave., Suite 500, Berkeley, CA 94720-7380, USA;

E-mail: kwan@berkeley.edu

Received 27 April 2005; revised 6 June 2005; accepted 13 June 2005; published online 19 July 2005;
Given that breastfeeding is a potentially relevant immunological exposure during a critical developmental period, we examined this in relation to ALL risk in the Northern California Childhood Leukaemia Study (NCCLS). Initiation, duration, and exclusivity of breastfeeding were investigated along with complimentary early feeding characteristics such as age when the child first drank formula or milk, type of formula or milk consumed, and type of solid food eaten.

\section{MATERIALS AND METHODS}

\section{Study population}

The NCCLS is an ongoing, approximately population-based casecontrol study that began in 1995. This analysis consists of data collected from two phases of the study: Phase one from 19 August 1995 to 30 November 1999 and Phase two from 1 December 1999 to 30 November 2002. Incident childhood leukaemia cases were identified using the International Classification of Diseases for Oncology (ICD-O) criteria (ICDO, 2000) with rapid case ascertainment procedures from seven (Phase one) and expanded to nine (Phase two) pediatric hospitals in the Northern and Central California study region. During Phase one, the study area consisted of 17 counties in Northern California, and then during Phase two, the area was extended to include 18 counties in Central California. Comparison with the statewide California Cancer Registry for 2000 showed that 95 and $76 \%$ of eligible cases among residents in the five counties San Francisco-Oakland Metropolitan Statistical Area and in the other 30 counties of the study area, respectively, were identified by the NCCLS protocol. The evaluation of case ascertainment for all 35 counties is currently underway. Cases were 
eligible if they were under 15 years of age, had no previous history of any malignancy, lived within the study region, and their parents spoke either English or Spanish. The study was approved by the University of California Committee for the Protection of Human Subjects, the California Health and Human Services Agency Committee for the Protection of Human Subjects, and the institutional review boards of the participating hospitals. Written informed consent was obtained from the parents of all participating study subjects.

After each case was identified, a control subject was randomly selected from birth certificates supplied by the California Birth Registry. Birth certificates were matched 1:1 (Phase one) or 1:2 (Phase two) to the case on date of birth, sex, Hispanic ethnic status (a child is considered Hispanic if either parent is Hispanic), maternal race, and maternal county of residence at birth (in Phase one) and maternal residence in 35 counties of the study area (in Phase 2). For cases not born in California (7\%), controls were selected from the case county of residence at diagnosis. Inclusion of cases born out of state was demonstrated to not modify study results in earlier analyses (Jensen et al, 2004; Kwan et al, 2004a).

As of 1 December 2002, 283 case-control pairs and 100 casecontrol triplets were available for analysis. Since the immunophenotype and likely the etiology of infant leukaemia differs from the other childhood leukaemias (Ross, 1998, 2000), 19 cases and their respective controls who were diagnosed during the first year of life were excluded, leaving 266 pairs and 98 triplets for analysis. Of these, 222 pairs and 89 triplets were of ALL subtype, and the remaining 44 pairs and eight triplets were of acute myeloblastic leukaemia (AML) subtype and one triplet was of juvenile myelomonocytic leukaemia (JMML) subtype.

The overall case participation rate was $86 \%$, while the overall control participation rate (number of eligible participating controls divided by the total number of eligible controls) was $85 \%$. Including all potential controls (eligible, not located, and refused) in the calculation yielded a participation rate of $57 \%$. Reasons for nonparticipation of the eligible and presumed eligible controls included refusals (25\%) and not located (18\%). Details of control participation in this analysis are provided in Figure 1. Further details of NCCLS control recruitment is given elsewhere (Ma et al, 2004).

\section{Data collection and management}

Information regarding breastfeeding and complimentary feeding characteristics was collected by an in-home interview and a selfadministered questionnaire, respectively. Most often, the biological mother provided the information on both instruments (95\%). Respondents were asked if they ever breastfed their child for at least 1 day (ever/never) and for how long (in months, weeks, or days). Specific feeding characteristics of interest were the age the child started drinking milk or formula, the type of milk or formula consumed at or before 6 months and after 6 months of age, the age child started eating solid foods, and the type of solid food consumed.

Breastfeeding was analysed as a binary (ever/never) variable. Duration of breastfeeding was analysed as reported (continuous) in months and as categories of none, less than, or equal to 3 months, 4-6 months, 7-12 months, and greater than or equal to 13 months. Exclusive breastfeeding (in relation to consuming other milk or formula) was derived from duration of breastfeeding (continuous) and the age when the child was first introduced to formula or milk (categorical) and was categorised as formula only, breast milk only for less than or equal to 3 months, 4-6 months, 7-12 months, and greater than or equal to 13 months.

\section{Statistical analysis}

Childhood leukaemia is a heterogeneous disease defined by various morphological and immunological criteria. The analyses of breastfeeding as well as complimentary feeding characteristics and risk of childhood leukaemia were restricted to ALL since the hypothesis regarding these potential associations is specific for ALL. Given that the peak incidence of ALL as well as its 'common' subtype $(\mathrm{CD} 10+, \mathrm{CD} 19+)$ is from age $2-5$ years (Swensen et al,

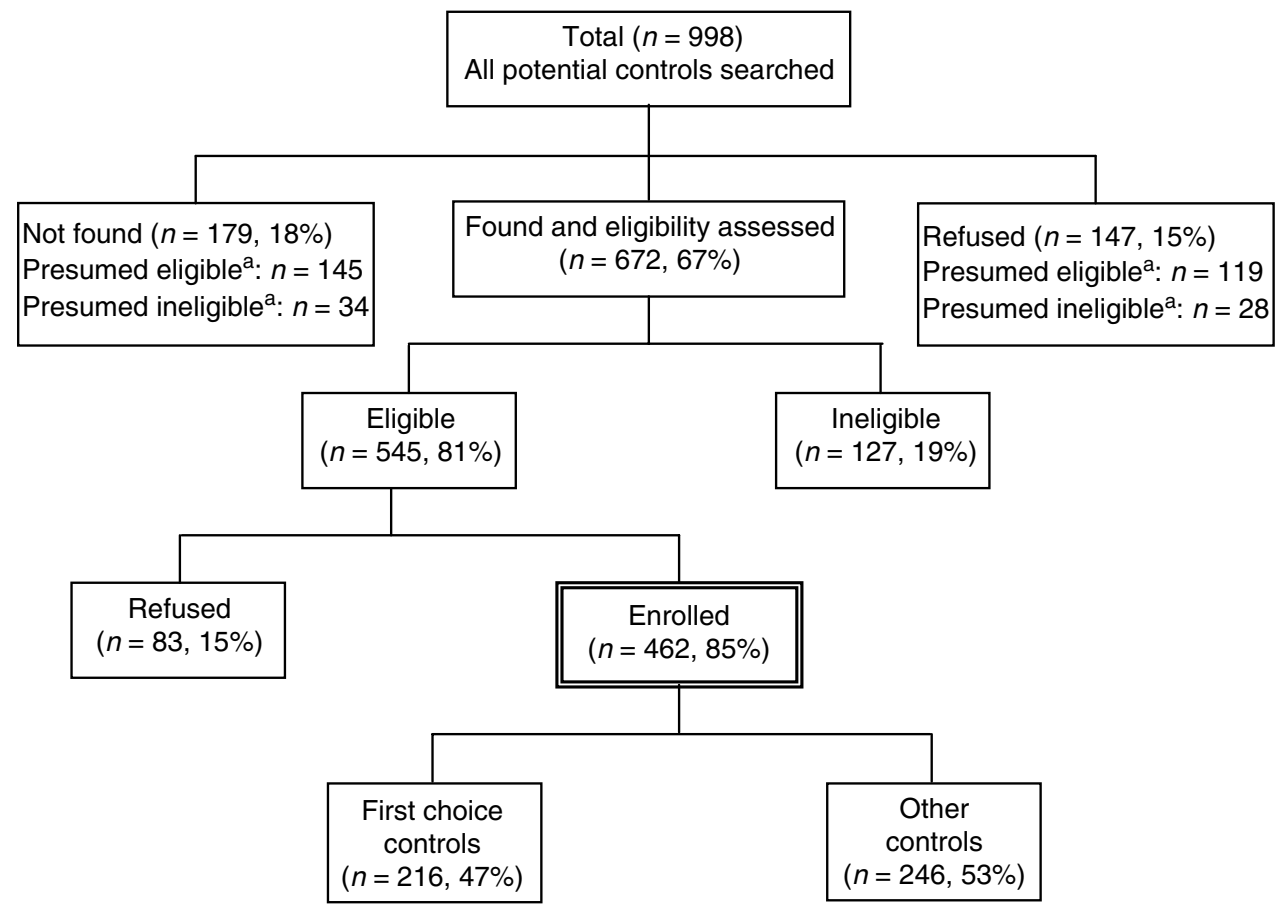

Figure I Control selection strategy in the NCCLS for the breastfeeding patterns analysis (19 August 1995 to 30 November 2002 ). ${ }^{a}$ Assuming the same percentage of eligible as that in potential controls who were found and whose eligibilities were assessed. 
1997; Smith et al, 1999), analyses were also performed utilising only these cases aged 2-5 years at diagnosis and their respective controls. Baseline characteristics of cases and controls were compared with the Pearson chi-square test. To assess the association between breastfeeding and other early feeding patterns and risk of ALL, conditional logistic regression models were used. Odds ratios (ORs) were considered to be consistent with statistical significance if their 95\% confidence intervals (CIs) excluded 1.00 . Confounding and effect modification were examined by using chi-square tests to compare the likelihood ratio statistics of the models with and without inclusion of confounding factors (annual household income and maternal education) and interaction terms (child's Hispanic status and phase of data collection). $P$-values $<0.05$ are considered significant for additive models, while $P$-values $<0.20$ are used for interaction terms in nonadditive models to increase the probability of detecting interactions that may be present. Since child's Hispanic status and phase of data collection were not significant $(P \geqslant 0.20)$, an additive conditional logistic model was assumed (Hosmer and Lemeshow, 2000).

\section{RESULTS}

The ALL cases and controls were similar with respect to birth weight and maternal age at birth (Table 1). Compared to controls, more leukaemia cases came from families with lower annual household income $(P<0.001)$ and were born to mothers with fewer years of maternal education $(P=0.07)$. The study sample consisted of $38 \%$ Hispanic, $50 \%$ non-Hispanic white, $3 \%$ non-Hispanic black, and $9 \%$ other. Frequency of ever breastfeeding was $81 \%$ in the cases and $84 \%$ in the controls.

After adjusting for household income and maternal education, ever compared to never breastfed $(\mathrm{OR}=0.99 ; 95 \% \mathrm{CI}=0.64-1.55)$ and breastfeeding duration in months $(\mathrm{OR}=1.00 ; 95 \% \mathrm{CI}=0.98-$ 1.02) were not associated with risk of ALL (Table 2). Similarly, when compared to no breastfeeding, breastfeeding less than or equal to 3 months, 4-6 months, 7-12 months, and greater than 13 months were not associated with ALL risk, and the $P$-value for trend across the categories was not significant. In addition, exclusivity of breastfeeding was examined to assess the independent biological effects of breast milk on the risk of ALL (Table 2). Feeding only breast milk for any length of time was not associated with ALL risk, and no significant trend across the categories existed. Restricting the analysis to ALL cases and their respective controls diagnosed from age 2-5 years revealed elevated, statistically nonsignificant effect estimates for breastfeeding and risk of disease (Table 2). Results for cALL cases and controls $(\mathrm{CD} 10+, \mathrm{CD} 19+)$ were also of similar magnitude and direction (not shown).

The associations of complimentary early feeding characteristics with risk of ALL from age 1 to 14 years and age $2-5$ years among children who were breastfed were also examined. For both age groups, type of milk/formula used at or before 6 months and after 6 months, age started eating solid foods, and type of solid food had no significant effect on risk of ALL (not shown).

\section{DISCUSSION}

This study investigated the role of breastfeeding and other early childhood feeding patterns as they relate to risk of childhood ALL. Breastfeeding was not associated with risk of ALL among children diagnosed between age 1 and 14 years or between age 2 and 5 years. In children who were breastfed, none of the complimentary feeding characteristics such as type of milk/formula used at or before age 6 months, age started eating solid foods, and type of solid food/baby food was associated with ALL risk.

To date, 13 case-control studies (Davis et al, 1988; Magnani et al, 1988; van Duijn et al, 1988; Shu et al, 1995; Petridou et al,
Table I Selected characteristics of non-infant (age I-14 years) childhood acute lymphoblastic leukemia (ALL) cases and controls in the Northern California Childhood Leukemia Study (NCCLS), 1995-2002

\begin{tabular}{|c|c|c|c|}
\hline & Cases $n$ (\%) & Controls $n(\%)$ & $P$-value $\left(\chi^{2} \text { test }\right)^{a}$ \\
\hline $\begin{array}{l}\text { Child age (years) } \\
1-1.99 \\
2-5 \\
6-10 \\
11-14 \\
\text { Mean (years) } \pm \text { s.d. }\end{array}$ & $\begin{array}{l}26(8) \\
186(60) \\
70(23) \\
29(9) \\
5.5 \pm 3.3\end{array}$ & $\begin{array}{l}34(8) \\
244(61) \\
83(21) \\
39(10) \\
5.4 \pm 3.3\end{array}$ & - \\
\hline $\begin{array}{l}\text { Child sex } \\
\text { Male } \\
\text { Female }\end{array}$ & $\begin{array}{l}164(53) \\
147(47)\end{array}$ & $\begin{array}{l}208(52) \\
192(48)\end{array}$ & - \\
\hline $\begin{array}{l}\text { Child race/ethnicity }^{\mathrm{b}} \\
\text { Hispanic } \\
\text { Non-Hispanic white } \\
\text { Non-Hispanic black } \\
\text { Other }\end{array}$ & $\begin{array}{c}116(38) \\
157(50) \\
9(3) \\
29(9)\end{array}$ & $\begin{array}{c}152(38) \\
200(50) \\
11(3) \\
37(9)\end{array}$ & - \\
\hline $\begin{array}{l}\text { Birth weight (g) } \\
\quad<2500 \\
2500-2999 \\
3000-3499 \\
\geqslant 3500 \\
\text { Unknown } \\
\text { Mean }(\mathrm{g}) \pm \text { s.d. }\end{array}$ & $\begin{array}{c}19(6) \\
52(17) \\
107(36) \\
122(41) \\
11 \\
3405.8 \pm 615.4\end{array}$ & $\begin{array}{c}20(5) \\
57(14) \\
140(36) \\
175(45) \\
8 \\
+3446.1 \pm 581.0\end{array}$ & 0.59 \\
\hline $\begin{array}{l}\text { Maternal age at birth (years) } \\
\quad<25 \\
25-34 \\
\geq 35 \\
\text { Unknown } \\
\text { Mean (years) } \pm \text { s.d. }\end{array}$ & $\begin{array}{c}108(35) \\
162(52) \\
39(13) \\
2 \\
28.0 \pm 6.0\end{array}$ & $\begin{array}{c}110(28) \\
232(58) \\
57(14) \\
\mid \\
28.7 \pm 5.9\end{array}$ & 0.11 \\
\hline $\begin{array}{l}\text { Maternal education } \\
\leqslant \text { High school } \\
\text { Some post-high school } \\
\text { College graduate } \\
\text { Unknown }\end{array}$ & $\begin{array}{r}135(43) \\
89(29) \\
86(28) \\
\text { । }\end{array}$ & $\begin{array}{c}|4|(35) \\
\mid 37(34) \\
\mid 22(3 \mid) \\
0\end{array}$ & 0.07 \\
\hline $\begin{array}{l}\text { Annual household income, } \$ \\
\quad<15000 \\
15000-29999 \\
30000-44999 \\
45000-59999 \\
60000-74999 \\
\geqslant 75000\end{array}$ & $\begin{array}{l}42(13) \\
61(20) \\
50(16) \\
58(19) \\
31(10) \\
69(22)\end{array}$ & $\begin{array}{l}37(9) \\
56(14) \\
47(12) \\
61(15) \\
52(13) \\
147(37)\end{array}$ & $<0.001$ \\
\hline Total & $311^{c}$ & $400^{c}$ & \\
\hline
\end{tabular}

${ }^{a}$ Pearson $\chi^{2}$ test; two-sided. ${ }^{b}$ For Phase one (19/8/1995-30/II//999), cases and controls I : I matched on date of birth, sex. Hispanic ethnic status, maternal race, and maternal county of residence at birth. For Phase two (1//21999-30/I I/2002), cases and controls I: I and I:2 matched on date of birth, sex, Hispanic ethnic status, and maternal race. Age is age at diagnosis for cases and age at the corresponding date for controls. ' $A$ total of 222 I : I case-control pairs and 89 1:2 case-control triplets.

1997; Dockerty et al, 1999; McKinney et al, 1999; Schüz et al, 1999; Rosenbaum et al, 2000; Hardell and Dreifaldt, 2001; UK Childhood Cancer Study Investigators, 2001; Lancashire and Sorahan, 2003; Jourdan-Da Silva et al, 2004) have reported no association between breastfeeding and overall childhood leukaemia or ALL risk. Two of these previous studies restricted their analysis to children diagnosed between age 2 and 5 years and found no significant effect of breastfeeding on risk of leukaemia (Shu et al, 1995; UK Childhood Cancer Study Investigators, 2001). In contrast, five 
Table 2 Results of matched analysis for initiation, duration, and exclusive breastfeeding and risk of non-infant childhood acute lymphoblastic leukemia (ALL) from age I to 14 years and age 2 to 5 years in the NCCLS, 1995-2002

\begin{tabular}{|c|c|c|c|c|c|c|}
\hline & \multicolumn{3}{|c|}{ Age $1-14$ years } & \multicolumn{3}{|c|}{ Age $2-5$ years } \\
\hline Ever & 248 & 334 & $0.99(0.64-1.55)$ & 158 & 203 & $1.49(0.83-2.65)$ \\
\hline \multicolumn{7}{|l|}{ Breastfeeding duration } \\
\hline 4-6 months breastfed & 51 & 74 & $0.84(0.48-1.47)$ & 28 & 46 & $1.07(0.50-2.25)$ \\
\hline 7-12 months breastfed & 56 & 89 & $0.88(0.5 I-1.53)$ & 34 & 53 & $1.29(0.63-2.67)$ \\
\hline$\geqslant 13$ months breastfed & 44 & 56 & $\begin{array}{l}1.08(0.61-1.92) \\
P \text { trend } \\
b=0.75\end{array}$ & 33 & 31 & 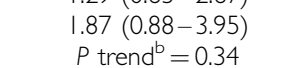 \\
\hline Breastfeeding duration (in months) & 305 & 398 & $1.00(0.98-1.02)$ & 183 & 243 & $1.02(0.99-1.05)$ \\
\hline$\geqslant 13$ months breast milk only & 16 & 26 & $0.86(0.38-1.92)$ & 12 & 13 & $2.04(0.69-6.07)$ \\
\hline
\end{tabular}

${ }^{a} \mathrm{OR}$, odds ratio; $\mathrm{Cl}$, confidence interval. $\mathrm{OR}$ and $\mathrm{Cl}$ derived from conditional logistic regression, which accounts for matching on child's date of birth, sex, Hispanic ethnic status, maternal race, and maternal county of residence at birth (only Phase one). Adjusted for annual household income and maternal education. ${ }^{b}$ Derived from treating the categorical variables on an ordinal scale in the conditional logistic regression model.

case-control studies (Shu et al, 1999; Smulevich et al, 1999; Infante-Rivard et al, 2000; Bener et al, 2001; Perrillat et al, 2002a, b) have reported a statistically significant protective association between breastfeeding and risk of either childhood ALL or overall leukaemia. One of these studies described a borderline statistically significant effect of breastfeeding on risk of ALL among children diagnosed less than 4 years of age (InfanteRivard et al, 2000). Control selection strategies in all of these breastfeeding studies included the use of population-based (11 studies), hospital-based (five studies), and random digit dial (RDD) (two studies) controls with sample sizes varying from a low of 63 cases of all leukaemia (Davis et al, 1988) to a high of 2200 cases of all leukaemia (Shu et al, 1999). Most of the statistical analyses adjusted for some measure of socioeconomic status such as household income, social class, parental occupation, or parental education.

In this analysis of NCCLS data, we were able to examine the 2-5 year diagnostic age group, which represents the peak incidence of c-ALL (Swensen et al, 1997; Smith et al, 1999), and to use detailed exposure assessment of breastfeeding initiation, duration, and exclusivity, the latter of which has not been explored in prior studies. Earlier, we evaluated selection bias by conducting an analysis of 64 pairs of matched birth certificate and friend controls from the study and 192 'ideal' population-based controls chosen randomly from birth records for the study area (Ma et al, 2004). After comparing data on parental age, parental education, mother's reproductive history, and birth weight, all variables, except birth weight, showed no significant differences between participating birth certificate and 'ideal' controls as compared to that between participating friend and 'ideal' controls. These results suggest that the NCCLS birth certificate controls are representative of the source population from which the cases arose.

The prevalence of having ever breastfed in the control group (84\%) was greater in the NCCLS than other previous populations studied. For example, the prevalence of breastfeeding in three of the largest studies to date on breastfeeding and risk of childhood leukaemia (United Kingdom Childhood Cancer Study, Children's Cancer Group, and Oxford Survey of Childhood Cancers) was 62, 54, and 49\%, respectively (Shu et al, 1999; UK Childhood Cancer Study Investigators, 2001; Lancashire and Sorahan, 2003). Descriptive statistics from phase II (1991 - 1994) of the Third National Health and Nutrition Examination Survey (NHANES III) reported that $54 \%$ of US infants were ever breastfed (Li et al, 2002). The high prevalence of breastfeeding among the NCCLS controls might have hindered the ability to detect an association of breastfeeding with risk of childhood ALL since most of the controls (and cases) were exposed, that is, breastfed.

An inherent limitation of the NCCLS is that the exposure histories were obtained by self-report and after diagnosis. This is a potential drawback of any case-control study since biologic mothers of cases may recall certain exposures differently (more completely or influenced by the knowledge of their child's diagnosis) than biologic mothers of controls. This bias is unlikely to have been a major concern since there was no public perception at the time of data collection that breastfeeding (Davis, 1998) or other early feeding characteristics might be associated with childhood leukaemia. In addition, we attempted to minimise reporting differences by mailing preparatory materials to serve as an 'aide memoire' for the respondents prior to the in-home interview.

Strengths of the NCCLS include extremely rapid case ascertainment (within 24-48h), population-based selection of controls, detailed exposure assessment, and comprehensive analysis of early childhood nutrition in relation to childhood leukaemia risk. We established a hospital-based system of rapid case ascertainment in the source population to shorten the interval from the date of diagnosis to interview to maintain complete (or near complete) case ascertainment in the study area, and to obtain pretreatment biological specimens. Second, the method of selecting controls from the population-based statewide birth registry ensures that controls are identified from the same study base as cases (as detailed above). Third, the study benefited from a detailed 
exposure assessment of breastfeeding and other early childhood feeding characteristics. The biological mother was asked whether or not she breastfed and how many months she only breastfed, thus allowing the calculation of an exclusive breastfeeding variable for analysis. She was also asked what type of formula or milk her child drank at or before 6 months and after 6 months of age. Finally, we conducted an earlier analysis of childhood dietary data consisting of specific foods/food groups that emphasised the protective benefits of nutrition during the first 2 years of life in relation to risk of childhood leukaemia (Kwan et al, 2004a). This current analysis examined breastfeeding, the other important component of a child's early diet, thus providing a complete assessment of the potential associations between postnatal nutritional exposures and childhood leukaemia risk.

In conclusion, this investigation was a comprehensive examination of breastfeeding patterns and the risk of childhood ALL in an essentially population-based case-control study. No association between breastfeeding and risk of ALL was observed. Furthermore, other early childhood feeding characteristics among breastfed children were not associated with ALL risk. Overall, this study did not support the hypothesis that breastfeeding protects against the risk of childhood ALL.

\section{ACKNOWLEDGEMENTS}

This study was supported by two research grants from the National Institute of Environmental Health Sciences (PS42 ES04705 and R01 ES09137). We thank Dr Jim Feusner at Children's Hospital Oakland, Dr Gary Dahl at Packard Children's Hospital, Drs Katherine Matthay and Mignon Loh at University of California, San Francisco, Dr Vonda Crouse at Children's Hospital of Central California, Dr Kenneth Leung at Kaiser San Francisco Hospital, Dr Stacy Month at Kaiser Oakland Hospital, Drs Carolyn Russo and Alan Wong at Kaiser Santa Clara Hospital, and Dr Vincent Kiley at Kaiser Sacramento Hospital for assistance with recruiting patients; Dr Barbara Abrams for valuable suggestions regarding data analysis; Monique Does for supervising field work and interviews; and the study staff for their hard work and dedication.

\section{REFERENCES}

Bener A, Denic S, Galadari S (2001) Longer breast-feeding and protection against childhood leukaemia and lymphomas. Eur J Cancer 37: 234-238

Davis MK (1998) Review of the evidence for an association between infant feeding and childhood cancer. Int J Cancer Suppl 11: 29-33

Davis MK, Savitz DA, Graubard BI (1988) Infant feeding and childhood cancer. Lancet 2: 365-368

Dockerty JD, Skegg DC, Elwood JM, Herbison GP, Becroft DM, Lewis ME (1999) Infections, vaccinations, and the risk of childhood leukaemia. $\mathrm{Br} \mathrm{J}$ Cancer 80: 1483 - 1489

Doody MM, Linet MS, Glass AG, Friedman GD, Pottern LM, Boice Jr JD, Fraumeni Jr JF (1992) Leukemia, lymphoma, and multiple myeloma following selected medical conditions. Cancer Causes Control 3: 449-456

Greaves M (1999) Molecular genetics, natural history and the demise of childhood leukaemia. Eur J Cancer 35: 1941 - 1953

Greaves MF (1988) Speculations on the cause of childhood acute lymphoblastic leukemia. Leukemia 2: 120-125

Greaves MF, Wiemels J (2003) Origins of chromosome translocations in childhood leukaemia. Nat Rev Cancer 3: 639-649

Hardell L, Dreifaldt AC (2001) Breast-feeding duration and risk of malignant diseases in childhood in Sweden. Eur J Clin Nutr 55: 179-185

Heath Jr CW, Hasterlik RJ (1963) Leukemia among children in a suburban community. Am J Med 34: 796-812

Hosmer D, Lemeshow S (2000) Appl Log Regression. New York

ICDO (2000) International Classification of Diseases for Oncology, 3rd edn. International Classification of Disease for Oncology. Geneva: World Health Organization

Infante-Rivard C, Fortier I, Olson E (2000) Markers of infection, breastfeeding and childhood acute lymphoblastic leukaemia. Br J Cancer 83: $1559-1564$

Jensen CD, Block G, Buffler P, Ma X, Selvin S, Month S (2004) Maternal dietary risk factors in childhood acute lymphoblastic leukemia (United States). Cancer Causes Control 15: 559-570

Jourdan-Da Silva N, Perel Y, Mechinaud F, Plouvier E, Gandemer V, Lutz P, Vannier JP, Lamagnere JL, Margueritte G, Boutard P, Robert A, Armari C, Munzer M, Millot F, De Lumley L, Berthou C, Rialland X, Pautard B, Hemon D, Clavel J (2004) Infectious diseases in the first year of life, perinatal characteristics and childhood acute leukaemia. Br J Cancer 90: $139-145$

Kinlen L (1988) Evidence for an infective cause of childhood leukaemia: comparison of a Scottish new town with nuclear reprocessing sites in Britain. Lancet 2: $1323-1327$

Kinlen LJ (2000) Infection, childhood leukaemia and the seascale cluster. Radiol Prot Bull 226: 9-18

Kwan ML, Block G, Selvin S, Month S, Buffler PA (2004a) Food consumption by children and the risk of childhood acute leukemia. Am J Epidemiol 160: $1098-1107$

Kwan ML, Buffler PA, Abrams B, Kiley VA (2004b) Breastfeeding and the risk of childhood leukemia: a meta-analysis. Public Health Rep 119: $521-535$
Lancashire RJ, Sorahan T (2003) Breastfeeding and childhood cancer risks: OSCC data. Br J Cancer 88: 1035 - 1037

Li R, Ogden C, Ballew C, Gillespie C, Grummer-Strawn L (2002) Prevalence of exclusive breastfeeding among US infants: the Third National Health and Nutrition Examination Survey (Phase II, 1991-1994). Am J Public Health 92: $1107-1110$

Ma X, Buffler PA, Layefsky M, Does MB, Reynolds P (2004) Control selection strategies in case-control studies of childhood diseases. Am J Epidemiol 159: 915 - 921

Ma X, Buffler PA, Selvin S, Matthay KK, Wiencke JK, Wiemels JL, Reynolds P (2002) Daycare attendance and risk of childhood acute lymphoblastic leukaemia. Br J Cancer 86: 1419-1424

Magnani C, Pastore G, Terracini B (1988) Infant feeding and childhood cancer [letter]. Lancet 2: 1136

McHale CM, Wiemels JL, Zhang L, Ma X, Buffler PA, Guo W, Loh ML, Smith MT (2003) Prenatal origin of TEL-AML1-positive acute lymphoblastic leukemia in children born in California. Genes Chromosomes Cancer 37: $36-43$

McKinney PA, Juszczak E, Findlay E, Smith K, Thomson CS (1999) Pre- and perinatal risk factors for childhood leukaemia and other malignancies: a Scottish case control study. Br J Cancer 80: 1844-1851

Perrillat F, Clavel J, Auclerc MF, Baruchel A, Leverger G, Nelken B, Philippe N, Schaison G, Sommelet D, Vilmer E, Hemon D (2002a) Day-care, early common infections and childhood acute leukaemia: a multicentre French case-control study. Br J Cancer 86: 1064-1069

Perrillat F, Clavel J, Jaussent I, Baruchel A, Leverger G, Nelken B, Philippe N, Schaison G, Sommelet D, Vilmer E, Hemon D (2002b) Breast-feeding, fetal loss and childhood acute leukaemia. Eur J Pediatr 161: $235-237$

Petridou E, Trichopoulos D, Kalapothaki V, Pourtsidis A, Kogevinas M, Kalmanti M, Koliouskas D, Kosmidis H, Panagiotou JP, Piperopoulou F, Tzortzatou F (1997) The risk profile of childhood leukaemia in Greece: a nationwide case-control study. Br J Cancer 76: 1241 - 1247

Rosenbaum PF, Buck GM, Brecher ML (2000) Early child-care and preschool experiences and the risk of childhood acute lymphoblastic leukemia. Am J Epidemiol 152: $1136-1144$

Ross JA (1998) Maternal diet and infant leukemia: a role for DNA topoisomerase II inhibitors? Int J Cancer Suppl 11: 26-28

Ross JA (2000) Dietary flavonoids and the MLL gene: a pathway to infant leukemia? Proc Natl Acad Sci USA 97: 4411 - 4413

Schüz J, Kaletsch U, Meinert R, Kaatsch P, Michaelis J (1999) Association of childhood leukaemia with factors related to the immune system. $\mathrm{Br} J$ Cancer 80: $585-590$

Severson RK, Davis S, Thomas DB, Stevens RG, Heuser L, Sever LE (1989) Acute myelocytic leukemia and prior allergies. J Clin Epidemiol 42: 995 1001

Shu XO, Clemens J, Zheng W, Ying DM, Ji BT, Jin F (1995) Infant breastfeeding and the risk of childhood lymphoma and leukaemia. Int $J$ Epidemiol 24: $27-32$ 
Shu XO, Linet MS, Steinbuch M, Wen WQ, Buckley JD, Neglia JP, Potter JD, Reaman GH, Robison LL (1999) Breast-feeding and risk of childhood acute leukemia. J Natl Cancer Inst 91: 1765-1772

Smith MA, Ries LAG, Gurney JG, Ross JA (1999) Leukemia. In Cancer Incidence and Survival among Children and Adolescents: United States SEER Program 1975-1995 Ries LAG, Smith MA, Gurney JG, Linet M, Tamra T, Young JL, Bunin GR (eds) pp. 17-34. Bethesda, MD: SEER Program, National Cancer Institute

Smulevich VB, Solionova LG, Belyakova SV (1999) Parental occupation and other factors and cancer risk in children: I. Study methodology and nonoccupational factors. Int J Cancer 83: 712 -717
Swensen AR, Ross JA, Severson RK, Pollock BH, Robison LL (1997) The age peak in childhood acute lymphoblastic leukemia: exploring the potential relationship with socioeconomic status. Cancer 79: 2045-2051

UK Childhood Cancer Study Investigators (2001) Breastfeeding and childhood cancer. Br J Cancer 85: 1685-1694

van Duijn CM, van Steensel-Moll HA, van der Does-vd Berg A, van Wering ER, van Zanen GE, Valkenburg HA, Rammeloo JA (1988) Infant feeding and childhood cancer [letter]. Lancet 2: 796-797

Wiemels JL, Cazzaniga G, Daniotti M, Eden OB, Addison GM, Masera G, Saha V, Biondi A, Greaves MF (1999) Prenatal origin of acute lymphoblastic leukaemia in children. Lancet 354: 1499-1503 